\section{Basic matters}

\section{B. Cantor}

Journal of Materials Science Letters.

Editor W. Bonfield.

Chapman \& Hall. 12/yr. £375, \$795.

Materials Letters.

Editors F.F. Wang and J.H. Wernick.

Elsevier. 6/yr. $\$ 90.75$.

Physics of Metals. (cover-to-cover

translation of Metallofizika.)

Editor-in-chief V.N. Gridnev.

Gordon \& Breach. 6/yr. £250, \$375.

MATERIALS science is about how to make use of our knowledge of the fundamental physics and chemistry of matter in order to manufacture useful engineering materials. The use of the term materials science is in fact relatively new and has grown steadily over the last ten or twenty years as scientists in previously separate disciplines - applied physicists and chemists, metallurgists, polymer scientists, ceramisists, etc - have increasingly come to realize that they share common aims and common methods of investigation. This trend can be seen reflected in the fortunes of the Journal of Materials Science, which was first published in 1966 with a quarterly issue of approximately 100 pages, and has grown to a monthly issue of over 300 pages. The publishers and editors of the Journal of Materials Science have now decided to hive off their letters section into a new and separate Journal of Materials Science Letters, and at virtually the same time another new journal has appeared called Materials Letters.

The two new journals have remarkably similar aims and content. Both journals are devoted exclusively to the rapid publication of short communications across the field of materials science, with articles of $1,000-2,000$ words, and a delay time of 3-4 months from submission of an article to its publication. Important scientific work should of course be published as soon as possible, and clear cut scientific results are often well suited to a short written format. However, there are dangers in rapid publication of short papers. Publishing quickly can all too easily lead to lower refereeing standards, and keeping a paper short can all too easily mean excluding background detail so that it becomes difficult to evaluate the scientific merit of the work. Judging by their first few issues, these two new journals have so far successfully avoided these difficulties, which are perhaps more severe with camera-ready papers published in conference proceedings.

Journal of Materials Science Letters is a monthly issue of approximately $\mathbf{4 0}$ pages, and continues to be sold together with its parent journal. Materials Letters is a bimonthly issue of approximately 30 pages. Both journals are presented attractively, and as with all broadly based materials science journals are a pleasure to read because of the diversity of scientific content. A single issue of the Journal of Materials Science Letters for instance includes articles on gallium arsenide semiconductors, high speed tool steels, graphite furnace elements, calcium tungstate scintillators, ceria refractory coatings, and polyethyleneterephthallate fibres. A similarly broad subject matter is also to be found in Materials Letters. The two journals are clearly competing for the same market, which is perhaps not large enough for both to be successful. In this respect the Journal of Materials Science Letters has the immediate advantage of an established set of contributors and readers.

The field of metal physics contains much which is part of materials science and is itself well catered for with journals such as the Journal of Physics, Physica Status Solidi, Philosophical Magazine, etc.

\section{Chemical regions}

\section{G.J. Leigh}

\section{Organometallics.}

Editor Dietmar Seyferth.

American Chemical Society. 12/yr. \$195.

Polyhedron: The International Journal

for Inorganic and Organometallic

Chemistry.

Editors-in-chief Geoffrey Wilkinson and

D.C. Bradley.

Pergamon. 12/yr. £250, $\$ 500$.

THESE journals are very different. Organometallics adds to the already wide spectrum of American Chemical Society (A.C.S.) publications. Polyhedron incorporates the Journal of Inorganic and Nuclear Chemistry and is envisaged as the inorganic and organometallic counterpart of Tetrahedron.

Organometallics published more than 1,700 pages in 1982 and the vast majority of the authors were from the United States. The new journal will be a focus for organometallic publication in North America, and it already publishes material which might otherwise have appeared in the Journal of the American Chemical Society or Inorganic Chemistry. Consequently, this journal is essential reading for all inorganic and organometallic chemists. The price is low, particularly for A.C.S. members.

The competing journal most likely to suffer is the Journal of Organometallic Chemistry. This has often been criticized because of its high price. It may well lose some US contributors and become more European in its constituency, but it will also always be required reading. Although covering similar fields, these two journals are not alternatives, but complementary.

Organometallics is well-presented and produced. Publication times can be as short as four months, six months is quite usual but delays of over a year were noted.
However, very little of the extensive Russian work in this field finds its way into these journals and most metal physicists, like all scientists, will be familiar with the difficulties of finding a Russian reference and obtaining a suitable English translation. The new journal Physics of Metals is therefore to be welcomed as a cover to cover English translation of the Russian journal Metallofizika, itself only published for the first time in 1979. This is a substantial journal, well presented and well translated, containing review articles, full length papers and short communications, although no book reviews. Unfortunately, the cost of the bimonthly issue of approximately 200 pages may mean that many libraries find it difficult to afford.

B.Cantor is a University Lecturer in the Department of Metallurgy and the Science of Materials, University of Oxford.

Polyhedron was introduced with the promise of rapid publication and good refereeing standards. Its constituency is European rather than American and very few papers originate from the USA. In 1982 , it published about 840 pages of text, slightly smaller in size than normal journal pages. Some of the issues were multiple (e.g. $7 / 8$ and $11 / 12$ ) which suggests that a year ago there may have been some shortage of contributions. It is doubtful whether this journal is necessary and it has not, so far, established a particular image. Nevertheless, the papers, varying in quality, cannot be ignored. The best are very good and are required reading.

Average publication times seem to be a little over four months. The quality of production is variable, papers may be typeset or photo-offset providing a change of style within one issue.

The journal also publishes reviews of an authoritative nature, and symposia. These will certainly be of value if they reach the standard of Tetrahedron Reports.

It is not clear whether either of these journals fills a gap in the current output of chemical literature or whether they can both maintain the standard of their contents. It has previously been argued that the learned societies, not being so subject to financial pressures as the commercial publisher, should better be able to maintain standards. The decline of the Journal of Inorganic and Nuclear Chemistry would support this view, and the editors of Polyhedron will have to work hard to avoid a similar fate.

In summary, both journals are required reading for inorganic and organometallic chemists. Probably neither was necessary but as they are here, libraries will need to take them. A personal subscription to either is very good value.

G.J. Leigh is Senior Principal Scientific Officer at the Agricultural Research Council, Unit of Nitrogen Fixation, University of Sussex. 